\title{
TRAINING ON THE BLENDED LEARNING DESIGN AS A SUPPLEMENT TO A LEARNING APPROACH AT PRIMARY SCHOOLS
}

\author{
SUHARTONO ${ }^{1}$, JAMALUDIN², Sri SUMIYATI ${ }^{3}$ \\ 1,2,3 FKIP Universitas Terbuka \\ Email: suhartono@ecampus.ut.ac.id
}

\begin{abstract}
SD Negeri Purworejo is a primary school with adequate learning facility, such as computer laboratories, projectors, and internet connection. Although teachers, students, and parents have the access and the skills to use information technology, the school facility has not been optimally used. It is assumed that the application of such skills and the use of school facility will improve the learning process and the students' learning outcomes. In this case, information technology is used to combine a face-to-face learning process and an online learning process, which is known as "blended learning". The twenty-four teachers of SD Negeri Purworejo did not have prior experience with the blended learning process, although they have the potential to apply it in their class. The solution for this is to hold a workshop on Blended Learning. The materials of the workshop should include blended learning planning, blended learning practical implementation, and information on the supporting materials required in blended learning. The methods used in the workshop are lecture, practicum, and simulation. The outcomes are offline and online lesson plans.
\end{abstract}

Key Words: learning approach, blended learning, primary school 


\section{PENDAHULUAN}

Kegemaran dan kemampuan siswanya dalam mengakses internet pun belum diadopsi oleh guru dalam pembelajaran. Kegemaran orang tua siswa menggunakan grup WA juga belum dimanfaatkan guru sebagai sarana melibatakan orang tua siswa dalam mendampingi anakanaknya di rumah dalam belajar. Hal ini diduga adanya Keterbatasan Guru-guru dalam berinteraksi dengan teknologi.

Guru-guru yang dimaksud adalah guru pada SD yang perlu dicarikan solusi agar aktifitas dan kreatifitas guru dalam pembelajaran semakin berkembang dengan memanfaatkan teknologi. Solusi tersebut perlu dilakukan secara komprehensif, terukur, dan terarah agar guru-guru terbantu dalam mendesain blended learning sebagai pendekatan pembelajaran di sekolah dasar. Muaranya adalah siswa dapat belajar lebih mudah, menyenangkan, efektif dan efesien dalam mempelajari berbagai materi yang sedang dipelajari di kelas. Kelengkapan fasilitas yang ada seperti Lab Komputer, LCD, jaringan internet, yang ditunjang dengan kemampuan guru, siswa, dan orang tua siswa mengakses internet dikombinasikan dalam kegiatan pembelajaran, maka kegiatan pembelajaran dapat lebih bervariasi, lebih menarik, lebih bermakna, lebih berkualitas, baik dalam proses maupun hasil pembelajaran. Kombinasi pembelajaran tatap muka dan pembelajaran onl;ine disebut dengan istilah "blended Learning" (Lin, W. S., \& Wang, C. H., 2012).

Pelatihan ini diharapkan dapat membantu guru-guru SD dalam mendesain blended learning sebagai suplemen pendekatan pembelajaran di sekolah dasar untuk digunakan sebagai pendekatan dalam pembelajaran di kelas yang menjadi tanggungjawabnya. Kepentingan pelaksanaan kegiatan ini adalah untuk meningkatkan kompetensi guru dalam mendesain blended learning sebagai suplemen pendekatan pembelajaran di sekolah dasar serta dapat menjadikan guru lebih profesional dalam melaksanakan tugas mengajar di kelas yang menjadi ttanggungjawabnya dengan menggunakan blended learning sebagai pendekatan pembelajaran.

\section{KAJIAN TEORI}

"Blended learning" merupakan istilah dari bahasa Inggris dan terdiri dari dua suku kata yaitu: "blended" (kombinasi/gabungan) dan "learning" (pembelajaran). Dengan kata lain "blended learning" dapat dimaknai sebagai pembelajaran kombinasi, yaitu gabungan / kombinasi pembelajaran secara tatap muka di kelas dan pembelajaran secara online dengan menggunakan aplikasi komputer yang tersambung dengan internet. Beberapa ahli mendefinisikan "blended learning" dengan redaksi yang berbeda-beda, tetapi dalam konsep yang sama atau hampir sama. Harding, Kaczynski dan Wood (Charman, 2005) menjelaskan bahwa blended learning merupakan pendekatan pembelajaran yang mengintegrasikan pembelajaran trade-sonal tatap muka dan pembelajaran jarak jauh yang menggunakan sumber belajar online dan beragam pilihan komunikasi yang dapat digunakan oleh guru dan siswa yang dapat diakses dari internet. Dengan demikian pendekatan ini memungkinkan penggunaan sumber yang ada di kelas seperti bukubuku yang tersedia di kelas dan sumber belajar online yang dapat disajikan secara bersama-sama dalam kegiatan tatap muka di kelas. 
Harriman (2004) dan Williams, (2003) memaknai "blended learning" sebagai penggabungan pembelajaran dengan beberapa metode penyampaian yang bertujuan untuk memberikan pengalaman yang paling efektif dan efisien. Penggabungan tersebut dapat berupa penggabungan berbagai teknologi pengajaran, misalnya penggabungan video, CD-ROM, film, atau internet dalam pengajaran tatap muka (face to face) yang dilakukan oleh guru dan siswa. Singh (2003) menyebutkannya istilah "blended e-learning". Pembelajaran dengan pendekatan "blended" dapat berbentuk pembelajaran tatap muka penuh dan pembelajaran on-line. Rancangan pembelajaran dengan "blended e-learning" perlu memperhatikan $3 \mathrm{c}$, yaitu: (1) content (isi materi pembelajaran), (2) communication (komunikasi antara siswa dan guru serta antarsiswa sendiri), dan (3) construction (penciptaan kondisi mental pembelajar untuk membantu memetakan posisi mereka dalam pembelajaran)

Kerres and De Witt (2003). Martyn (2003) mengatakan bahwa suatu lingkungan "blended e-learning" dapat disajikan dalam satu pertemuan awal yang sepenuhnya tatap muka (face to face), penugasan online mingguan disertai dengan komunikasi (konsultasi) online, e-mail, dan ditutup dengan satu ujian akhir yang berupa tatap muka atau ujian tulis di kelas dengan dibantu pengawas. Dengan demikian, siswa mempunyai kesempatan untuk mengembangkan diri serta bertanggung jawab terhadap diri sendiri. Hooper, (1992); Saunders \& Klemming, (2003), menyebutnya sebagai upaya meningkatkan kompetensi sosial dan kepercayaan diri siswa (Byers, 2001) dalam (Kendall, 2001), menyebutnya sebagai upaya meningkatkan keterampilan menggali informasi dan meraih prestasi. Selain itu, guru juga akan lebih menghargai berbagai perbedaan dalam gaya dan kecepatan belajar masing-masing siswa. Blended e-learning juga dapat mendorong komunikasi antarsiswa sendiri dan antara siswa dan guru (Joliffe, Ritter, \& Stevens, 2001). (Piskurich, 2004).

Dengan blended learning pembelajaran menjadi lebih bermakna karena pembelajaran menggunakan beragam sumber belajar seperti buku-buku yang tersedia di kelas dan media lain yang diakses dari internet. Kegiatan belajar mengajar tidak hanya terbatas pada waktu belajar di kelas tetapi juga dapat diteruskan oleh siswa diwaktu dan tempat lain di luar kelas. Kegiatan di luar kelas dengan internet didasarkan pada tugas yang diberikan oleh guru di ruang kelas, dikerjakan di luar kelas dan dibahas kembali hasilnya di ruang kelas tatap muka pada pertemuan berikuitnya. Dengan demikian kegiatan siswa mengakses media pembelajaran di luar kelas secara online terkontrol oleh guru dan hasil evaluasinya diperhitungkan sebagai hasil belajar siswa sebagai bahan penentuan peringkat dan kenaikan kelas di atasnya. Di samping itu siswa dapat berbagi pengalaman belajar dan berdiskusi dengan siswa lain baik yang ada pada siswa lain dalam kelas yang sama dan siswa lain dari sekolah yang berbeda secara online.

Dengan kata lain blended learning merupakan pendekatan pembelajaran yang memadukan pertemuan tatap muka dengan materi online secara harmonis. Perpaduan antara pembelajaran konvensional berbentuk face to face siswa dan pembelajaran online dilakukan pada waktu dan tempat yang berbeda tentu dalam batas waktu yang telah disepakati antara guru dan siswa untuk dibahas pada pertemuan tatap berikutnya. Semler (2005) mengatakan bahwa: "blended leraning" mengombinasikan aspek terbaik dari pembelajaran online, aktivitas tatap muka terstruktur, dan praktik dunia nyata. Sistem pembelejaran online, latihan di kelas, dan pengalaman belajar di luar 
kelas (mandiri) akan memberikan pengalaman berharga bagi siswa. Blended learning dapat memanfaat beragam media belajar baik yang tersedia di kelas maupun yang tersedia di internet sebagai sumber informasi sehingga pembelajaran menjadi bermakna

Pembelajaran dengan blended learning memungkinkan terjadinya pertemuan virtual antara guru dan siswa pada waktu dan tempat yang berbeda, tetapi mereka dapat saling memberikan balikan atas hasil kerja, siswa dapat bertanya, atau menjawab yang dilakukan dalam waktu nyata seperti dalam tatap muka. Beberapa islilah sebagai padanan dari blended learning "Iong distance instructed learning" (Pembelajaran Jarak Jauh". Ada yang menyebutnya sebagai "virtual instructor led training, training" (pembelajaran maya) dengan guru yang sebenarnya tetapi berhubungan secara maya karena antara guru dan siswa berada di tempat yang berbeda dengan memanfaatkan media komputer yang tersambung dengan internet. "Blended learning" dapat dilaksa-nakan dengan memanfaatkan media "video conference, phone conference, atau chatting online."

Kelebihan "blended leaning" adalah bahwa pembelajaran dapat efisien dan efektif . Pembelajaran tatap muka memungkinkan pembelajaran berlangsung secara interaktif dengan menggunakan berbagai pendekatan, strategi serta metode pembelajaran sedangkan penambahan pembelajaran secara online dapat dapat memberikan materi secara online tanpa batasan ruang dan waktu, dengan materi yang lebih beragam (menanfaatkan gambar foto, video, bacaan virtual yang diakses dari internet), sehingga pembelajaran menjadi lebih menarik dan bermakna. Kelebihan lain pembelajaran dengan pendekatan blended learning adalah seswa dalam belajar mandiri di luar kelas dapat dibantu oleh orang lain seperti orang tua dan orang dewasa lain (kakak dan teman) dalam mengakses dan menjelasan materi yang tersaji di internet.

\section{METODE PELAKSANAAN}

Metode pelatihan dilakukan dengan teknik, antara lain :

(1) Menjelaskan konsep blended learning dari pengertian, model, panduan pelaksanaan blended learning. Di sekolah dasar.

(2) Memberikan contoh perencaan pembelajaran dengan blended learning di sekolah dasar.

(3) Pendampingan dilakukan ketika guru-guru melakukan kegiatan perencanaan, ketika mengunduh materi dari internet, ketika menyimpan, ketika memindahkan, dan ketika menggunakan materi yang telah diunduh dari internet, baik melalui media WA maupun edmodo. Di dalam pendampingan juga diadakan sharing pendapat dalam bentuk:
a. Diskusi
b. Pemberian pertimbangan yang logis
c. Penguatan keputusan 


\section{a. Strategi dan Solusi}

(1) Strategi pendekatan yang digunakan dalam program abdimas ini berbentuk presentasi dan pendampingan. Presentasi difokuskan pada penyamaan persepsi tentang konsep blended learning sedangkan pendampingan diberikan untuk membantu guru-guru dalam berlatih mendesain blended learning sebagai pendekatan pembelajaran. Pelatihan dan pendampingaqn ini difokuskan pada:

(2) Teknik mengunduh dan menyimpan materi pembelajaran dari internet, baik materi berupa teks, foto, maupun video.

(3) Teknik memindahkan materi pembelajaran yang telah diunduh dari internet ke dalam grub WA atau ke aplikasi edmodo.teknik membuat dan menggunakan blog sebagai sumber dan media pembelajaran.

(4) teknik membuat grup dan memanfaatkan WA dan atau edmodo sebagai saluran pembelajaran. "Blended learning" dapat dimaknai sebagai pembelajaran kombinasi, yaitu kombinasi pembelajaran secara tatap muka di kelas dan pembelajaran secara online dengan menggunakan aplikasi komputer yang tersambung dengan internet. Beberapa ahli mendefinisikan "Blended learning" dengan redaksi yang berbeda-beda, tetapi dalam konsep yang sama atau hampir sama. Harding, Kaczynski dan Wood (Charman, 2009) menjelaskan bahwa "Blended learning" merupakan pendekatan pembelajaran yang mengintegrasikan pembelajaran tradisonal tatap muka dan pembelajaran jarak jauh yang menggunakan sumber belajar online dengan beragam pilihan komunikasi yang dapat digunakan oleh guru dan siswa yang diakses dari internet.

(5) Harriman (2004) memaknai "Blended learning" sebagai penggabungan pembelajaran dengan beberapa metode penyampaian yang bertujuan untuk memberikan pengalaman yang efektif dan efisien. Penggabungan ini dapat berbentuk penggabungan berbagai teknologi pengajaran, yaitu pembelajaran tatap muka (face to face) dengan pemanfaatan video, CD-ROM, filem, yang diunduh dari atau diakses dari internet.

(6) Semler (2005) mengatakan bahwa: "blended leraning" mengombinasikan aspek terbaik dari pembelajaran online, aktivitas tatap muka terstruktur, dan praktik dunia nyata. Sistem pembelejaran online, latihan di kelas, dan pengalaman belajar di luar kelas (mandiri) akan memberikan pengalaman berharga bagi siswa. "Blended learning" dapat memanfaat beragam media belajar baik yang tersedia di kelas maupun yang tersedia di internet sebagai sumber informasi sehingga pembelajaran menjadi bermakna.

(7) Dengan "blended learning" kualitas pembelajaran dapat ditingkatkan. Hooper, (1992); menyebutkan bahwa "Blended learning" dapat meningkatkan kompetensi sosial dan kepercayaan diri siswa. Kendall, (2001), menyebutkan bahwa blended learning dapat meningkatkan keterampilan menggali informasi dan meraih prestasi. Dengan "Blended learning" guru dapat lebih menghargai berbagai perbedaan dalam gaya dan dalam kecepatan belajar masing-masing siswa. Karena "Blended learning" berbasis on-line, maka 
dapat mendorong komunikasi antarsiswa, mendorong komunikasi atara siswa dan guru, baik dari dalam satu sekolah maupun dengan guru dan siswa dari sekolah lain.

(8) Pembelajaran dengan "Blended learning" memungkinkan terjadinya pertemuan virtual antara guru dan siswa pada waktu dan tempat yang berbeda, tetapi mereka dapat saling memberikan balikan atas hasil kerjanya. Siswa dapat bertanya, atau menjawab yang dilakukan dalam waktu nyata seperti dalam tatap muka. Ada yang menyebutnya sebagai "virtual instructor led training, training "(pembelajaran maya) dengan guru yang sebenarnya tetapi berhubungan secara maya karena antara guru dan siswa berada di tempat yang berbeda dengan memanfaatkan media komputer yang tersambung dengan internet. Blended learning dapat dilaksanakan dengan memanfaatkan media "video conference, phone conference, atau chatting online."

\section{b. Instrumen Intervensi}

Instrumen intervensi yang digunakan dalam kegiatan abdimas ini mengacu pada teknik intervensi yang sesuai dengan karakteristik pembelajaran dengan blended learning, yaitu berupa:

1. kegiatan menjelaskan konsep blended learning sebagai pendekatan pembelajaran di sekolah dasar

2. kegiatan pembimbingan dalam mendesain pembelajaran dengan pendekatan blended learning di sekolah dasar.

3. Kegiatan pembimbingan praktik mengunduh, menyimpan, memindahkan dan menggunakan berbagai materi yang telah diunduh dari internet untuk digunakan sebagai mmedia pembelajaran blended learning di sekolah dasar.

4. Kegiatan memanfaatkan Grub WA dan Edmodo sebagai saluran pembelajaran on-line

5. Kegiatan memberikan motovasi kepada guru mitra untuk memulai menggunakan pendekatan blended learning di sekolah dasar baik dalam bentuk off-line maupun on-line.

\section{c. Peta Wilayah / Masyarakat Tempat Abdimas}

Kegiatan abdimas ini dilaksanakan di SD Negeri Purworejo, UPTD Dibudpora Kecamatan Purworejo, Kabupaten Purworejo. Lokasi ini terletak disebelah timur alun-alun Purworejo, terletak di pusat kota dapat dijangkau dengan semua jenis angkutan kota, lancar, tidak macet, dan sangat kondusif untuk kegiatan pelatihan. Di SD Negeri di setiap kelasnya Purworejo terdapat lab komputer, LCD, dan memiliki jaringan internet. 


\section{HASIL DAN PEMBAHASAN}

Pelatihan ini bertujuan untuk membekali guru-guru SD Negeri Purworejo dalam mendesain dan melaksanakan pembelajaran dengan blended learning. Materi yang dilatihkan meliputi konsep blended learning, perencanaan pembelajaran, praktik dengan blended learning dan kemampuan pendukung sebagai prasyarat untuk dapat melaksanakan pembelajaran dengan blended learning. Kemampuan pendukung yang diperlukan dalam pembelajaran dengan blended learning adalah kemampuan mengunduh, menyimpan, dan menggunakan berbagai media pembelajaran dari internet, seperti mengunduh teks, suara, dan video dari internet. Praktik menggunduh menggunakan aplikasi savefrom-net, teknik pemindahan atau mentransfer materi dengan dari handphone ke komputer atau PC dan atau sebaliknya digunakan aplikasi buetooth. Sedangkan teknik mengkoversi media pembelajaran digunakan aplikasi format factori. Kemampuan lainnya adalah kemampuan menginstall aplikasi pembelajaran on-line, seperti membuat grub WA dan aplikasi edmodo sebagai saluran pembelajaran on-line yang bisa dimanfaatkan sebagai saluran untuk menyajikan pembelajaran dengan blended learning dalam bentuk on-line.

Jumlah gruru SD Negeri Purworejo sebagai peserta pelatihan 24 orang, terdiri dari 12 guru kelas, 9 guru bidang studi 1 guru agama, dan 2 guru olah raga. Pelatihan diberikan dalam 4 pertemuan. Metode yang digunakan dalam pelatihan adalah metode ceramah, praktik, dan simulasi. Hasilnya semua peserta dapat mengahasilkan produk pelatihan berupa perencanaan pembelajaran dengan blended learning, baik yang disajikan secara off-line maupun secara on-line. Khusus sajian secara on-line dirancang dalam saluran grup WA dan aplikasi edmodo. Dengan rincian 4 guru menggunakan edmodo, 9 orang menggunakan grub WA, sedangkan sisanya 11 orang masing menggunakan blended learning model off-line.l

Partisipasi orang tua yang secara langsung dapat dideteksi ada partisipasi pembelajaran yang dilakukan guru melalui saluran edmodo dan grub WA. sedangkan ii kelas lainnya yang menggunakan blended learning dengan versi off-line tidak dapat diteksi secara langsung. Versi terakhir ini hanya bisa dilakukan dengan wawancara dan pengamatan secara langsung. Dan pada pelatihan ini kegiatan teralhir ini belum dilakukan.

\section{KESIMPULAN}

Pelatihan ini dapat disimpulkan berhasil. Bukti yang menunjukkan hal tersebut adalah bahwa 22 guru dapat merencanakan pembelajaran dengan pendekatan blended learning. Hanya 2 guru tidak terdektsi karena tidak membuat perencanaan dengan dengan blended learning. Keduanya adalah guru olah raga. Dari 24 guru peserta pelatihan, 13 orang menggunakan blended learning dengan model on-line, terdiri dari 4 orang guru menggunakan saluran edomodo, dan 9 orang menggunakan grup WA. Sisanya 11 orang menggunakan model off-line. 


\section{DAFTAR PUSTAKA}

Charman, Jared M. (2009) Blended Learning Design: Five Key Ingredients, Director, Product Development Knowledge Net, October 2002 www.brandon-hall.com. Erişim tarihi: 15 February 2009 dalam http://www.ubicc.org/files/pdf/1_355.pdf diunduh 12 Juli 2017

Kendall, M. (2001). Teaching Online To Campus-Based Students: The Experience Of Using Webct For The Community Information Module At Manchester Metropolitan University. Education For Information, 19(4), 325-346.

Lin, W. S., \& Wang, C. H. (2012). Antecedences to continued intentions of adopting e-learning system in blended learning instruction: A contingency framework based on models of information system success and task-technology fit. Computers \& Education, 58(1), 88-99

Muhammad Zakaria. (tanpa tahun). Pengertian, Manfaat, dan Fitur-Fitur yang Wajib Anda Ketahui dalam http://www.nesabamedia.com/pengertian-manfaat-dan-fitur-edmodo/, diunduh 168-2017

Prima Suci R. (2013). Dalam makalahnya berjudul Blended Learning Dan Peluangnya dalam https://primazip.wordpress.com/2013/06/10/blended-learning-dan-peluangnya/ diunduh 10 Agustus 2017

Semler, S. (2005) Use Blended Learning to Increase Learner Engagement and Reduce Training Cost. (On-line)

dalam http://www.learningsim.com/content//snews/blended_learning1.html. Diunduh 11 Agustus 2017 